\title{
A novel stability indicating HPLC-method for simultaneous determination of atenolol and nifedipine in presence of atenolol pharmacopeoial impurities
}

\author{
Hisham Hashem ${ }^{1,2^{*}}$, Ibrahim Adel Ehab ${ }^{3}$, Elhenawee Magda ${ }^{1}$ \\ ${ }^{1}$ Faculty of Pharmacy, Pharmaceutical Analytical Chemistry Department, Zagazig University, Egypt. \\ ${ }^{2}$ Faculty of Pharmacy, Pharmaceutical Chemistry Department, Jazan University, Saudi Arabia. \\ ${ }^{3}$ Egyptian International Pharmaceutical Industries Co. "EIPICo", Tenth of Ramadan City, Egypt.
}

\begin{tabular}{|c|c|}
\hline ARTICLE INFO & ABSTRACT \\
\hline Articl & \multirow{10}{*}{ 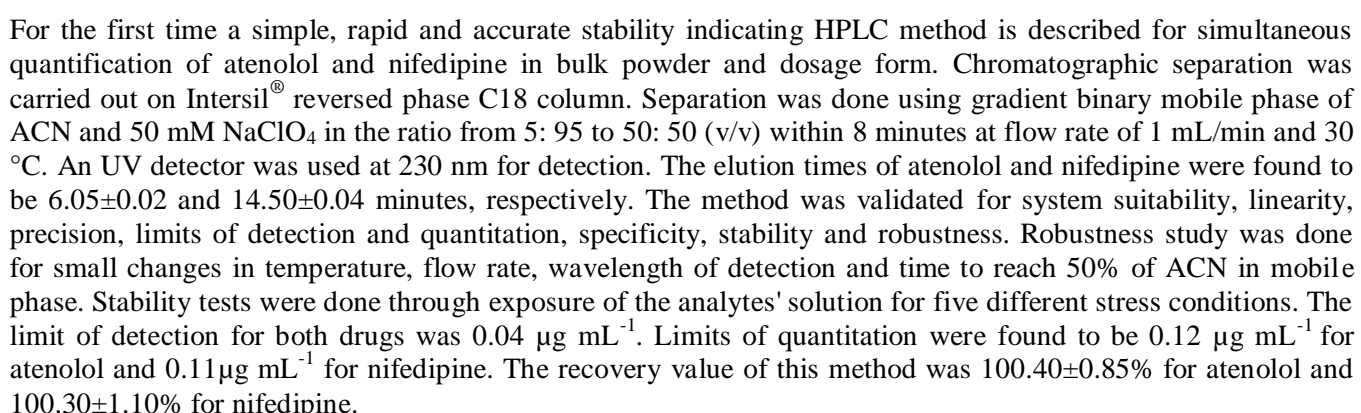 } \\
\hline$/ 05 / 2015$ & \\
\hline Revised & \\
\hline Acce & \\
\hline Available onlin & \\
\hline Key words: & \\
\hline Atenolol and nifedipine, & \\
\hline Quantitative HPLC- & \\
\hline determination, Stability & \\
\hline $\begin{array}{l}\text { indicating, Pharmacopeoial } \\
\text { impureties. }\end{array}$ & \\
\hline
\end{tabular}

\section{INTRODUCTION}

Atenolol, 4-(2-hydroxy-3-isopropylamminopropoxy) phenylacetamide (Fig. 1), is a cardioselective beta blocker lacking intrinsic sympathomimetic activity. It is clinically used in the management of hypertension, angina pectoris, cardiac arrhythmias and myocardial infarction (Sweetman, 2006). Like other antihypertensive drugs, atenolol lowers the systolic and diastolic blood pressure by $15-20 \%$ in a single drug treatment and reduces cardiovascular mortality. It is also used alone or in combination with other antihypertensive agents for the treatment of myocardial infarction, arrhythmias, angina and disorders arising from decreased circulation and vascular constriction, including migraine (Prichard et al., 2001). Nifedipine, 3, 5-dimethyl 2, 6-dimethyl-4-(2-nitrophenyl)-1, 4dihydropyridine-3, 5-dicarboxylate (Fig. 1), is a dihydropyridine

\footnotetext{
* Corresponding Author

Hisham Hashem, Analytical chemistry department, faculty of pharmacy, Zagazig university, Zagazig, Egypt. Email: hisham413@yahoo.com
}

calcium-channel blocker. It is a peripheral and coronary vasodilator that has little or no effect on cardiac conduction and negative inotropic activity at therapeutic doses. Combination therapy of atenolol and nifedipine is now common and available since studies revealed that the combination regimen significantly reduced supine and standing systolic and diastolic blood pressure compared with each drug alone. Heart rate was significantly decreased by the combination compared with nifedipine alone (Stanley et al., 1988).

In open literature, several methods have been reported for the determination of atenolol that relied on HPLC (Belal et al., 2013; Bing et al., 2004; Hui et al., 2004; Vidyadhara et al., 2012; Kallem et al., 2013), gas chromatographic techniques (Yilmaz and Arslan, 2011), high performance thin layer chromatography (HPTLC) (Ramteke et al., 2010), flourometry (Gajewska et al., 1992), differential scanning calorimetry (DSC) and thermogravimetry (TG) (Pyramides et al., 1995), electrophoresis (Azzam et al., 2009), electrochemical methods (Taei et al., 2015), atomic absorption spectrometry (AAS) (ElRies et al., 1995), UVand visible spectrophotometry (Prasad et al., 1998; Singh et al., 
1997; Ferraro et al., 2003; Umapathi, 1994; Kasture, 2005; Veronico et al., 1995; Sabel et al., 2012) and titrimetry (Prashanth et al., 2012). Atenolol was previously determined in combination with other beta-blockers (Yilmaz and Arslan, 2011), chlorthalidone (Azzam et al., 2009; Ferraro et al., 2003), amlodipine (Singh et al., 1997) and hydrochlorothiazide as well as amiloride (Prasad et al., 1998). HPLC method is being used most frequently for the trace analysis of nifedipine (Bing et al., 2004; Hui et al., 2004; Vidyadhara et al., 2012; Kallem et al., 2013; Asthana et al., 2010; El Walily, 1997; Ohkubo et al., 1992). Other instrumental techniques used for analysis of nifedipine are spectrophotometry (Umapathi, 1994; Kasture, 2005; Veronico et al., 1995; Sabel et al., 2012; El Walily, 1997; Shamsipur et al., 2003), gas chromatography (El Walily, 1997; Martens et al., 1994) and Spectrofluorometry (Al-Ghannam et al., 2008). Electrochemical methods had been also described for determination of nifedipine (Shapovalov et al., 2002; Squellaa et al., 1989). Nifedipine was previously analyzed in combination with nateglinide and lovastatin (Asthana et al., 2010), nicardipine and isradipine Martens et al., 1994) as well as acebutolol $\mathrm{HCl}$ (El Walily, 1997).

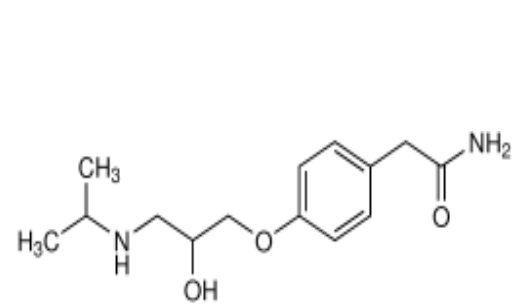

Atenolol

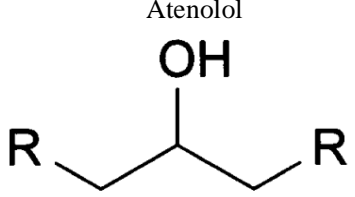

Atenolol impurity E

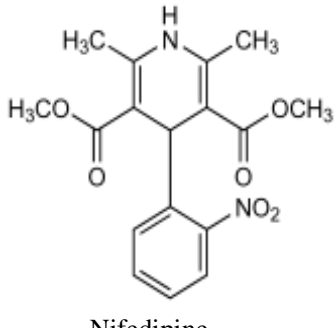

Nifedipine

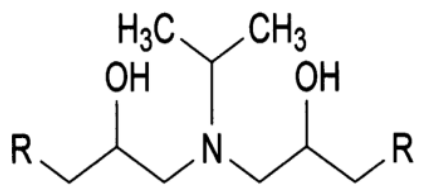

Atenolol impurity $\mathrm{F}$

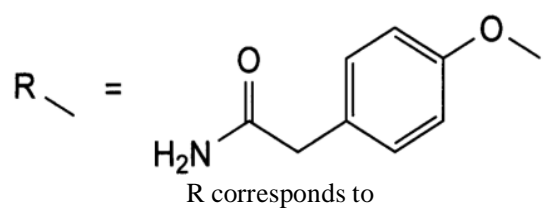

Fig. 1: Chemical structure of analytes and atenolol pharmacopeoial impurities.

Although there are various papers describing determination of each of atenolol and nifedipine alone or in combination with other drugs, only few papers described the determination of both drugs in combination by derivative spectrophotometry (Umapathi, 1994; Kasture, 2005; Veronico et al., 1995; Sabel et al., 2012), HPTLC (Ramteke et al., 2010) and liquid chromatographic methods (Bing et al., 2004; Hui et al., 2004; Vidyadhara et al., 2012; Kallem et al., 2013). In the reported LC-methods (Bing et al., 2004; Hui et al., 2004; Vidyadhara et al.,
2012; Kallem et al., 2013). For previously determination of both drugs in combination there are three limitations: Low sensitivity, use of ion pairing additive to facilitate the separation and these methods are not stability indicating methods. There is no a previous work dealt with stability indicating method for simultaneous determination of atenolol and nifedipine. In all reported stability indicating methods only one drug (atenolol or nifedipine) was determined. Handa et al., (2014) found that presence of atenolol with nifedipine in the same dosage form led to accelerate degradation of nifedipine. Thus, it was important to find a new sensitive stability indicating method without using ion pairing agent for simultaneous quantitative determination of both drugs in combination.

\section{MATERIALS AND METHODS}

\section{Chemicals and reagents}

All chemicals and reagents are at least analytical grade. Water was bidistilled, $\mathrm{NaClO}_{4}$ was purchased from (Merck). ACN was HPLC-grade (J.T. Baker). Atenolol and nifedipine pharmaceutical grade were obtained from (EIPICo). Pharmaceutical formulation, Tenolate $\mathrm{SR}^{\circledR}$ capsules (containing 20 $\mathrm{mg}$ nifedipine and $50 \mathrm{mg}$ atenolol per capsule) were obtained from Egyptian market.

\section{Instrumentation}

Agilent HPLC series 1200 (Agilent technologies) consists of solvent pump (model G1311A), autosampler (model G1329A), column compartment (model G1316A) and UV detector (model G1314A). SUNTEST CPS ${ }^{\circledR}$ was used for UV-radiation for photodegradation.

\section{Column}

C18 stationary phase column Intersil ${ }^{\circledR}$ ODS-3 (5 $\mu \mathrm{m}, 4.6$ x $150 \mathrm{~mm}$ ) was obtained from GL sciences Inc..

\section{Chromatography}

The experiments were performed with gradiant elution. The binary mobile phase consisted of $\mathrm{ACN}$ and $0.05 \mathrm{M} \mathrm{NaClO}_{4}$ (5: 95) at zero time to (50: 50) within the first 8 minutes then stayed 15 minutes 50: 50. The eluents were degassed before running, set at a flow rate of $1 \mathrm{mLmin}^{-1}$ and column temperature at $30{ }^{\circ} \mathrm{C}$. Volume of $20 \mu \mathrm{L}$ of samples was injected per run and eluates were detected using UV -Detector at $\lambda=230 \mathrm{~nm}$.

\section{Solutions preparation}

\section{Preparation of stock and standard working solutions}

The stock solutions of atenolol and nifedipine $(1 \mathrm{mg} \mathrm{mL}$ $\left.{ }^{1}\right)$ were prepared by dissolving $100 \mathrm{mg}$ of each in $(1: 1, \mathrm{v} / \mathrm{v}) \mathrm{ACN}$ : $\mathrm{H}_{2} \mathrm{O}$ to make $100 \mathrm{~mL}$ of solution. The standard working solutions were prepared by diluting aliquots of the stock solutions with $(1: 1$, v/v) ACN: $\mathrm{H}_{2} \mathrm{O}$ to obtain concentrations ranging from 2 to $50 \mu \mathrm{g}$ $\mathrm{mL}^{-1}$. The calibration graphs were constructed by plotting the peak areas obtained at wavelength $230 \mathrm{~nm}$ versus the corresponding injected concentrations. 


\section{Sample preparation}

The contents of 10 capsules of Tenolate $\mathrm{SR}^{\circledR}$ were accurately weighed as fine powder. To an accurately weighed portion of the powder equivalent to one capsule, $250 \mathrm{~mL}(1: 1)$ ACN: $\mathrm{H}_{2} \mathrm{O}$ was added then the solution was left in the ultrasonic bad for $5 \mathrm{~min}$. After that the solution was filtered and the first 10 $\mathrm{mL}$ was rejected then $5 \mathrm{~mL}$ of the filtrate was diluted to $100 \mathrm{~mL}$ using same solvent.

\section{Stability tests}

Forced degradation studies were performed to provide an indication of the stability-indicating properties and specificity of the method. Intentional degradation was attempted using acid, base, hydrogen peroxide, thermal and UV-radiation. A degradation sample was prepared by dissolving of $50 \mathrm{mg}$ atenolol and nifedipine, each in $50 \mathrm{~mL}\left(\mathrm{ACN}: \mathrm{H}_{2} \mathrm{O}, 1: 1\right)$ through shaking and sonication. Then $10 \mathrm{~mL}$ of each solution was transferred into each of three $50 \mathrm{~mL}$ round bottom flasks to perform the first three degradation tests. To the first flask $10 \mathrm{~mL}$ of $1 \mathrm{~N} \mathrm{HCl}$ was added for acidic degradation. To the second flask $10 \mathrm{~mL}$ of $1 \mathrm{~N} \mathrm{NaOH}$ was added for basic degradation and to the third flask $10 \mathrm{~mL}$ of $30 \% \mathrm{H}_{2} \mathrm{O}_{2}$ was added for oxidative degradation. Each of the three flasks was refluxed for about 4 hours.

After completing the degradation treatment, samples were allowed to cool to room temperature and treated as follows: The $\mathrm{pH}$ values of the first and second flasks were neutralized with $1 \mathrm{~N} \mathrm{NaOH}$ and $1 \mathrm{~N} \mathrm{HCl}$, respectively. To the third flask $1 \mathrm{~N}$ sodium bisulphite solution was added to destroy excess $\mathrm{H}_{2} \mathrm{O}_{2}$. The volume of all the three flasks was adjusted to $50 \mathrm{~mL}$ with $\left(\mathrm{ACN}: \mathrm{H}_{2} \mathrm{O}\right.$, $1: 1)$. For thermal degradation, powders of atenolol and nifedipine were dispersed onto Petri-dish and left in oven at $60^{\circ} \mathrm{C}$ for 4 hours then solution is prepared from them to concentration of $0.2 \mathrm{mg}$ $\mathrm{mL}^{-1}$ using (ACN: $\mathrm{H}_{2} \mathrm{O}, 1: 1$ ) as solvent. For degradation through $\mathrm{UV}$-radiation $2 \mathrm{~mL}$ of the sample solution was left in $\mathrm{UV}$ radiation for 4 hours then the radiated solution diluted with $\left(\mathrm{ACN}: \mathrm{H}_{2} \mathrm{O}\right.$, $1: 1)$ to $10 \mathrm{~mL}$, then finally injected into $\mathrm{LC}$ and compared with control sample. Samples were injected and analyzed against control samples (lacking of degradation treatment).

The stock solutions of the specified impurities of atenolol in British Pharmacopoeia (containing atenolol impurity $\mathrm{E}$ and impurity F (The British Pharmacopoeia, 2011)) (Fig. 1) were prepared in concentration of $0.1 \mathrm{mg} \mathrm{mL}^{-1}\left(\mathrm{ACN}: \mathrm{H}_{2} \mathrm{O}, 1: 1\right)$ as solvent.

\section{RESULTS AND DISCUSSION}

Different types of RP-HPLC-columns were examined for separation of intact drugs from their stress degradants and from each other applying isocratic mode but no column of them enabled the baseline separation. Thus gradient mode was applied. Using of methanol as organic modifier resulted in elongation of retention times; so ACN was used as organic modifier. Mobile phase including water without any salt as aqueous part gave bad separation due to tailing of peaks and this is why $\mathrm{NaClO}_{4}$ is added to aqueous part of the mobile phase. In previous studies, it was found that usage of $\mathrm{NaClO}_{4}$ as aqueous mobile additive (chaotropic mobile phase additive) led to reduction of retention times and enhancement of separation of basic analytes via decreasing of tailing (Elhenawee et al., 2014; Hashem et al., 2014). The method was validated according to ICH guidelines (Guidance for Industry: ICH 1996) for system suitability, linearity, precision, limits of detection and quantitation, specificity, stability and robustness. Robustness study was done for small changes in temperature, flow rate, wavelength of detection and time to reach $50 \%$ of ACN in mobile phase.

\section{System suitability}

The results of three runs indicate high system suitability (table 1). The $t_{R}$-values of atenolol and nifedipine are $6.05 \pm 0.02$ and $14.50 \pm 0.04 \mathrm{~min}$, respectively. The RSD of peak areas are 0.60 and $0.90 \%$ for atenolol and nifedipine, respectively.

Table.1: System suitability, linearity and regression data for atenolol and nifedipine.

\begin{tabular}{lll}
\hline Parameters & Atenolol & Nifedipine \\
\hline System suitability & & \\
$\mathrm{t}_{\mathrm{R}} \pm \mathrm{SD}(\mathrm{min})$ & $6.05 \pm 0.02$ & $14.50 \pm 0.04$ \\
$\mathrm{~N}$ & 6500 & 16000 \\
$\mathrm{k}$ & 3.9 & 9.5 \\
Linearity range $\left(\mu \mathrm{g} \mathrm{mL}^{-1}\right)$ & $2-25$ & $2-25$ \\
Detection limit $\left(\mu \mathrm{g} \mathrm{mL}^{-1}\right)$ & 0.04 & 0.04 \\
Quantitation limit $\left(\mu \mathrm{g} \mathrm{mL}^{-1}\right)$ & 0.12 & 0.11 \\
Regression data & & \\
Slope $(\mathrm{b})$ & 31.52 & 58.37 \\
Intercept (a) & -4.64 & -4.73 \\
Coefficient of determination $\left(\mathrm{R}^{2}\right)$ & 0.9999 & 0.9998 \\
\hline
\end{tabular}

\section{Linearity and Range}

Six concentrations of atenolol and nifedipine solutions ranging from 2 to $50 \mu \mathrm{g} \mathrm{mL}^{-1}$ were analyzed. The graph of the peak area against concentration proved linearity in the range of 2 $25 \mu \mathrm{g} \mathrm{mL}^{-1}$ and the linearity equation is: $\mathrm{Y}=31.518 \mathrm{X}-4.64$ and coefficient of determination equals 0.9999 for atenolol, while for nifedipine the linearity equation is: $\mathrm{Y}=58.374 \mathrm{X}-4.73$ and coefficient of determination equals 0.9998 . The limit of detection (LOD) defined as the injected quantity giving $\mathrm{S} / \mathrm{N}$ of 3.3 (in terms of peak height), was found to be $0.04 \mu \mathrm{g} \mathrm{mL}^{-1}$ for both atenolol and nifedipine. The limit of quantitation (LOQ) is defined as the injected quantity giving $\mathrm{S} / \mathrm{N}$ of 10 (in terms of peak height), was found to be $0.12 \mu \mathrm{g} \mathrm{mL} \mathrm{m}^{-1}$ for atenolol and $0.11 \mu \mathrm{g} \mathrm{mL} \mathrm{m}^{-1}$ for nifedipine (table 1).

\section{Accuracy and specificity of the method}

The accuracy of the method was determined by recovery\% using standard addition technique experiments $(n=5)$. Atenolol and nifedipine showed high accuracy with recovery of $100.40 \pm 0.85$ and $100.30 \pm 1.10 \%$, respectively (table 2 ).

The comparison between the chromatogram of the raw atenolol or nifedipine (fig. 2a) and that of extracted from their dosage form (fig. 2b) indicates that the excipients in the formulation did not interfere with their determination. Also no 
interference occurred from atenolol BP standard impurities (The British Pharmacopoeia, 2011) (fig. 2c). No interference was found from the following drugs: Amlodipine besylate, paracetamol, diazepam and hydrochlorothiazide, when they were simultaneously injected with atenolol and nifedipine.

Table 2: Accuracy of the proposed method applying standard addition technique $(\mathrm{n}=5)$.

\begin{tabular}{|c|c|c|c|c|c|}
\hline & Atenolol & & & Nifedi & \\
\hline 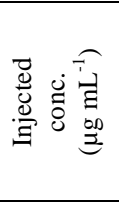 & 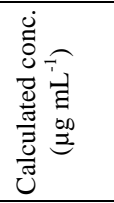 & 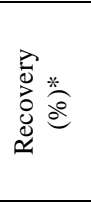 & 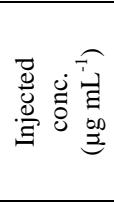 & 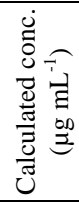 & 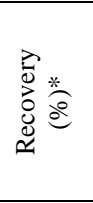 \\
\hline 3.48 & 3.48 & 100.00 & 3.24 & 3.26 & 100.52 \\
\hline 6.27 & 6.29 & 100.26 & 4.30 & 4.32 & 100.59 \\
\hline 7.77 & 7.83 & 100.76 & 8.59 & 8.54 & 99.37 \\
\hline 10.43 & 10.38 & 99.48 & 10.74 & 10.66 & 99.24 \\
\hline 16.69 & 16.97 & 107.73 & 17.18 & 17.52 & 101.90 \\
\hline \multicolumn{6}{|c|}{ Recovery $\% \pm$ RSD } \\
\hline \multicolumn{2}{|c|}{$100.40 \pm 0.85 \%$} & \multicolumn{2}{|c|}{$100.30 \pm 1.10 \%$} & & \\
\hline
\end{tabular}

The results of stress degradation indicate that atenolol is more affected with reflux with $\mathrm{NaOH}$ (fig. 3a) and $\mathrm{H}_{2} \mathrm{O}_{2}$ (fig. 3b), while nifedipine is more affected with $\mathrm{H}_{2} \mathrm{O}_{2}$ (fig. 4a). Reflux with $\mathrm{HCl}$ (figs. 3c and 4b) led to degradation of atenolol and nifedipine but the effect here is weaker than in case of $\mathrm{H}_{2} \mathrm{O}_{2}$ and $\mathrm{NaOH}$, while thermal (figs. $3 \mathrm{~d}$ and 4c) and UV-light exposures (figs. $3 \mathrm{e}$ and $4 \mathrm{~d}$ ) gave the minimum effect on both atenolol and nifedipine. Although there are several degradants, there was no interference with the peaks of the intact drugs indicating that the method is stability indicating.

\section{Stability of the analytical solution}

Stability of the standard solution was studied by injection of the prepared solution at periodic intervals into the chromatograph up to about five days. The results indicate that the RSD of the peak area was within $1.00 \%$ for both atenolol and nifedipine.

\section{Reproducibility and precision of the method}

Results (table 3) show that there were high intra- and inter-day precisions (both within $2.00 \%$ ). Intra-day precision was assessed through injection of the standard solution five times during a day at three concentrations. The same was done for interday precision test except that the injection of the samples was every day for five days.

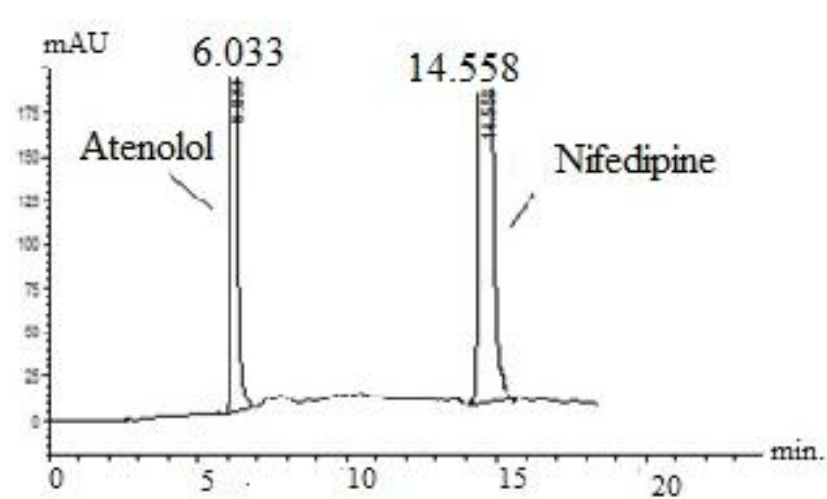

(A)

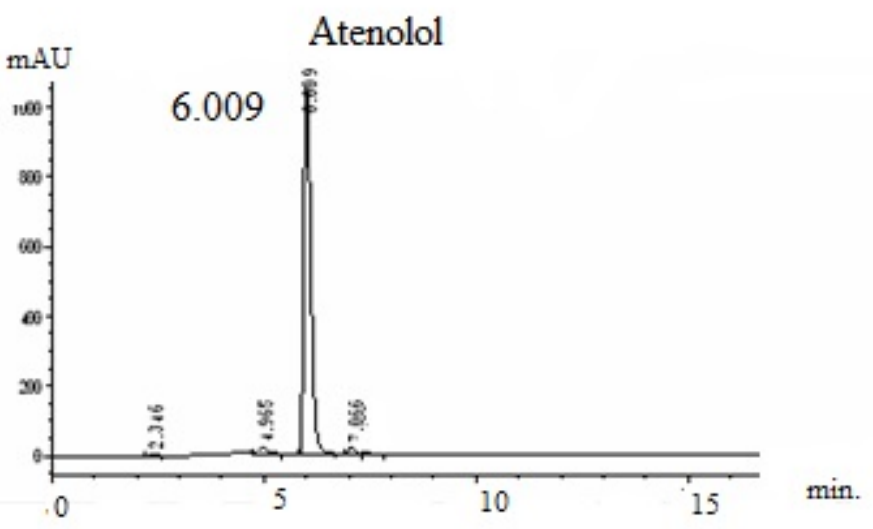

(C)

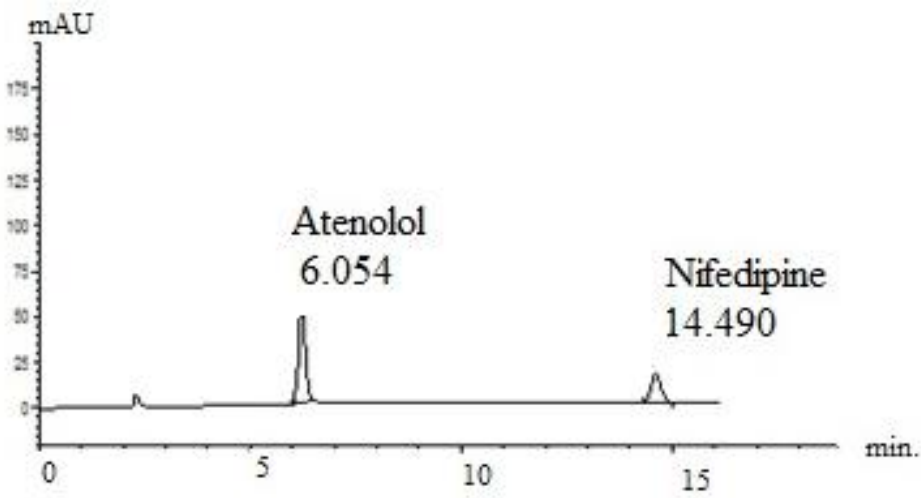

(B)
Fig. 2: Specificity of the proposed method., a- Atenolol and nifedipine from bulk powders., b- Atenolol and nifedipine from Tenolate $\mathrm{SR}^{\circledR}$ capsules., c- Atenolol impurity standard (Atenolol + impurities E and F). 

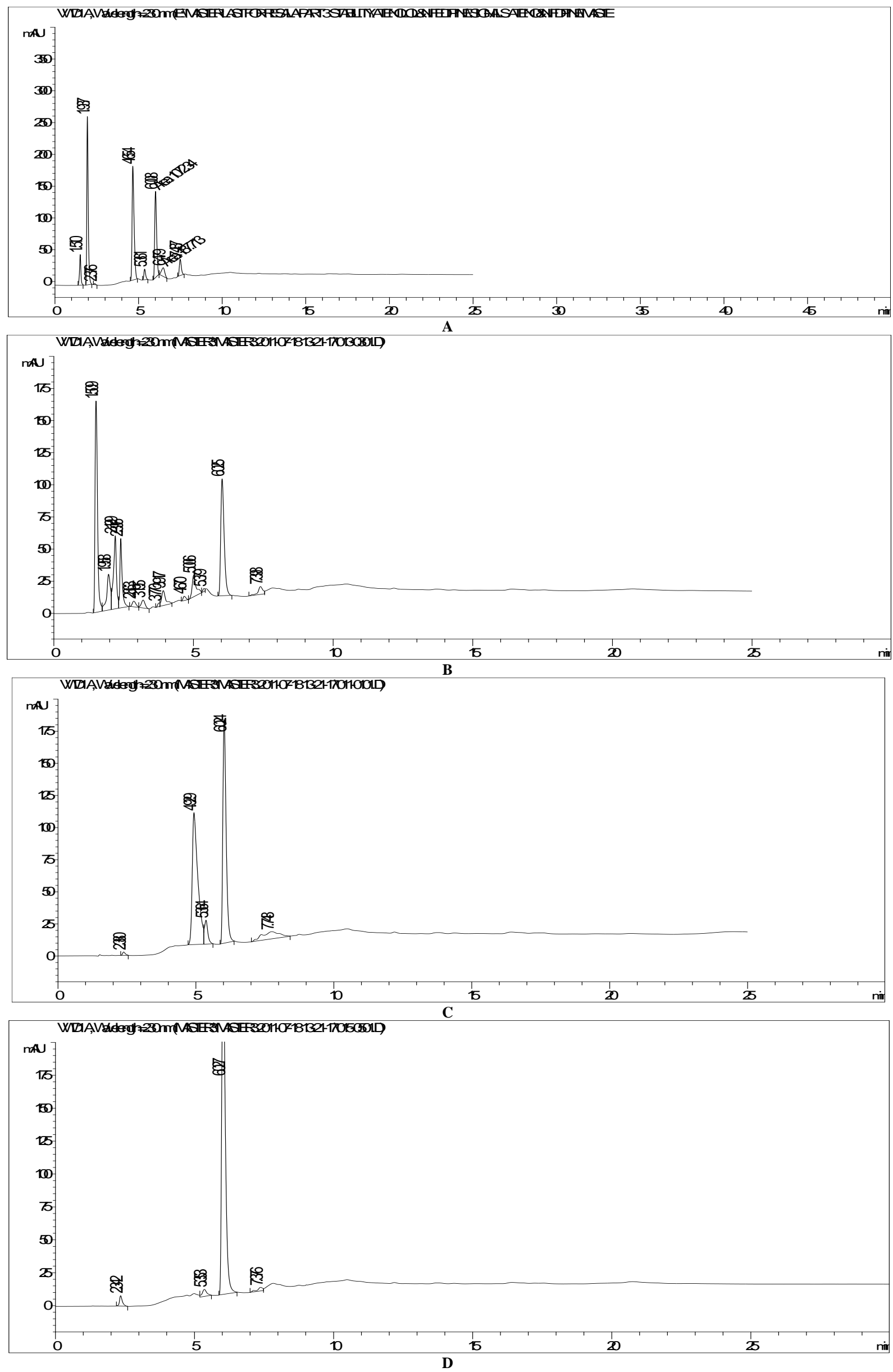


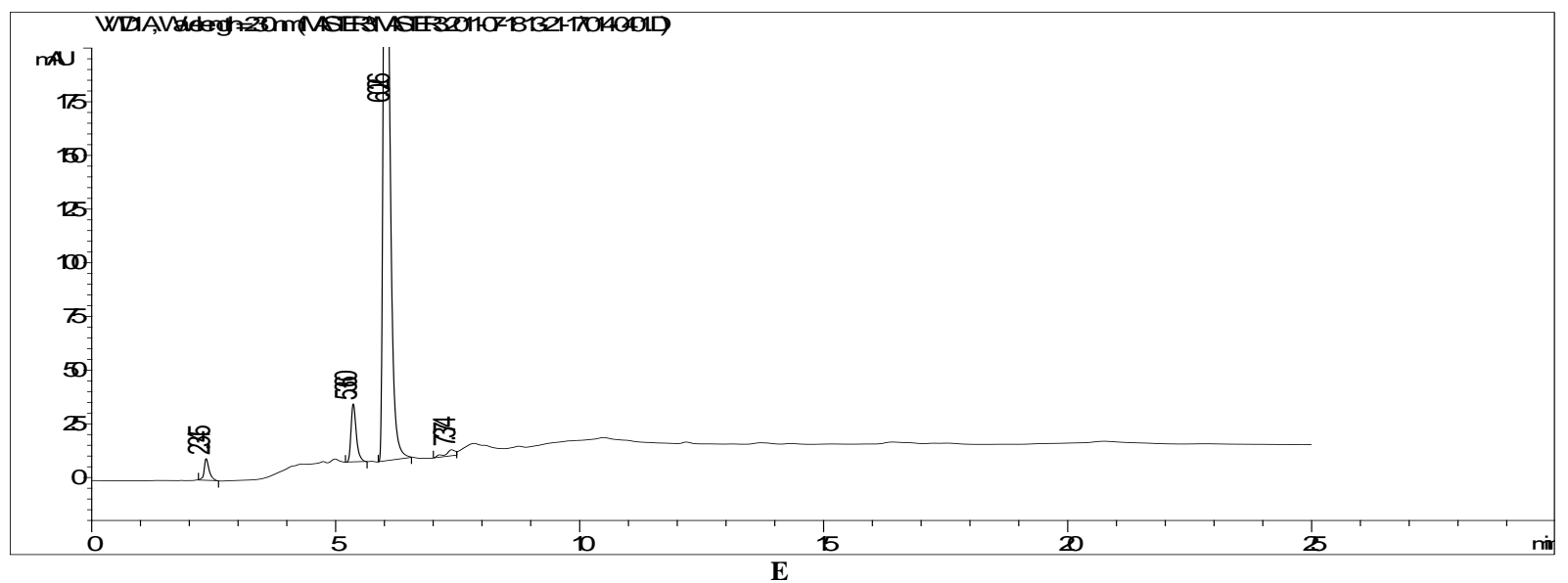

Fig. 3: Stress degradation of Atenolol, A: Atenolol after treatment with $1 \mathrm{~N} \mathrm{NaOH}$., B: Atenolol after treatment with $\mathrm{H}_{2} \mathrm{O}_{2}$., C: Atenolol after treatment with $1 \mathrm{~N}$ $\mathrm{HCl}$., D: Atenolol powder after exposure to heat $60^{\circ} \mathrm{C}$ for 4 hours., E: Atenolol after exposure to UV light at suntest ${ }^{\circledR}$ for 4 hours.

Table 3: Reproducibility and precision of the method.

\begin{tabular}{|c|c|c|c|c|c|c|}
\hline \multirow[b]{2}{*}{$\begin{array}{l}\text { Injected amount } \\
\qquad\left(\mu \mathrm{g} \mathrm{mL} \mathbf{L}^{-1}\right)\end{array}$} & \multicolumn{3}{|c|}{ Intra-day $(n=5)$} & \multicolumn{3}{|c|}{ Inter-day $(\mathrm{n}=5)$} \\
\hline & $\begin{array}{c}\text { Observed amount } \\
\left.(\mu \mathrm{g} \mathrm{mL})^{-1}\right)\end{array}$ & $\mathrm{CV} \% *$ & $\begin{array}{c}\text { Accuracy } \\
(\%)^{* *}\end{array}$ & $\begin{array}{c}\text { Observed amount } \\
\left.(\mu \mathrm{g} \mathrm{mL})^{-1}\right)\end{array}$ & CV \%* & Accuracy $(\%)^{* * *}$ \\
\hline 5.00 & 4.94 & 0.33 & 98.84 & 4.99 & 0.90 & 99.70 \\
\hline 10.00 & 9.99 & 0.10 & 99.89 & 10.07 & 0.85 & 100.70 \\
\hline 20.00 & 20.15 & 0.04 & 100.70 & 20.30 & 0.70 & 101.50 \\
\hline \multicolumn{7}{|c|}{ Atenolol } \\
\hline 10.08 & 10.08 & 0.68 & 100.00 & 10.08 & 0.50 & 100.00 \\
\hline 20.16 & 20.37 & 0.89 & 101.00 & 20.26 & 0.50 & 100.50 \\
\hline 25.20 & 25.04 & 0.74 & 99.40 & 24.96 & 0.38 & 99.04 \\
\hline \multicolumn{7}{|c|}{ Nifedipine } \\
\hline
\end{tabular}

*Coefficient of variation (\%) = S.D. /mean x 100., **Accuracy (\%) = observed concentration /used concentration x 100.

Table 4: Statistical comparison of the proposed method with a reported method (Vidyadhara et al., 2012)

\begin{tabular}{lllll}
\hline Drug & Atenolol & & Nifedipine & \\
\hline & Proposed method & Reported method (Vidyadhara et al., 2012) & Proposed method & Reported method (Vidyadhara et al., 2012) \\
\hline Mean \pm SD & $100.78 \pm 0.98$ & $100.18 \pm 0.76$ & $100.65 \pm 1.02$ & $100.19 \pm 0.92$ \\
N & 6 & 6 & 6 & 6 \\
RSD & 0.972 & 0.759 & 1.013 & 0.918 \\
V & 0.960 & 0.578 & 1.040 & 0.846 \\
Student-t & $1.185(2.20)^{*}$ & & $0.821(2.20)^{*}$ & \\
F-test & $1.660(4.12)^{*}$ & & $1.229(4.12)^{*}$ & \\
\hline
\end{tabular}

* The figures in parenthesis are the theoretical values for $\mathrm{t}$ - and $\mathrm{f}$-test at $(\mathrm{P}=0.05)$.

Table 5: Robustness of the proposed method.

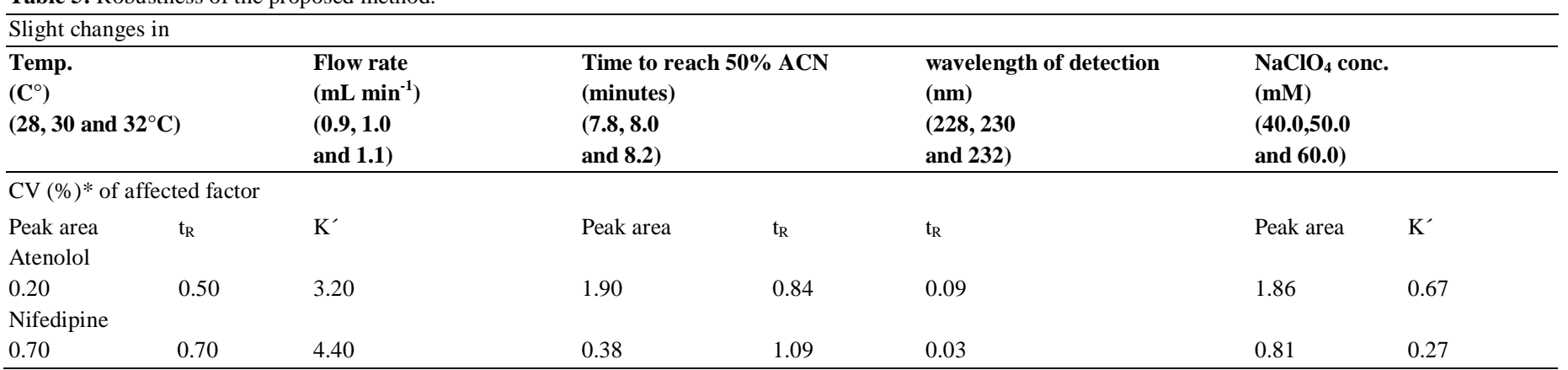

${ }^{*}$ Coefficient of variation $(\%)=$ S.D. /mean x 100 . 

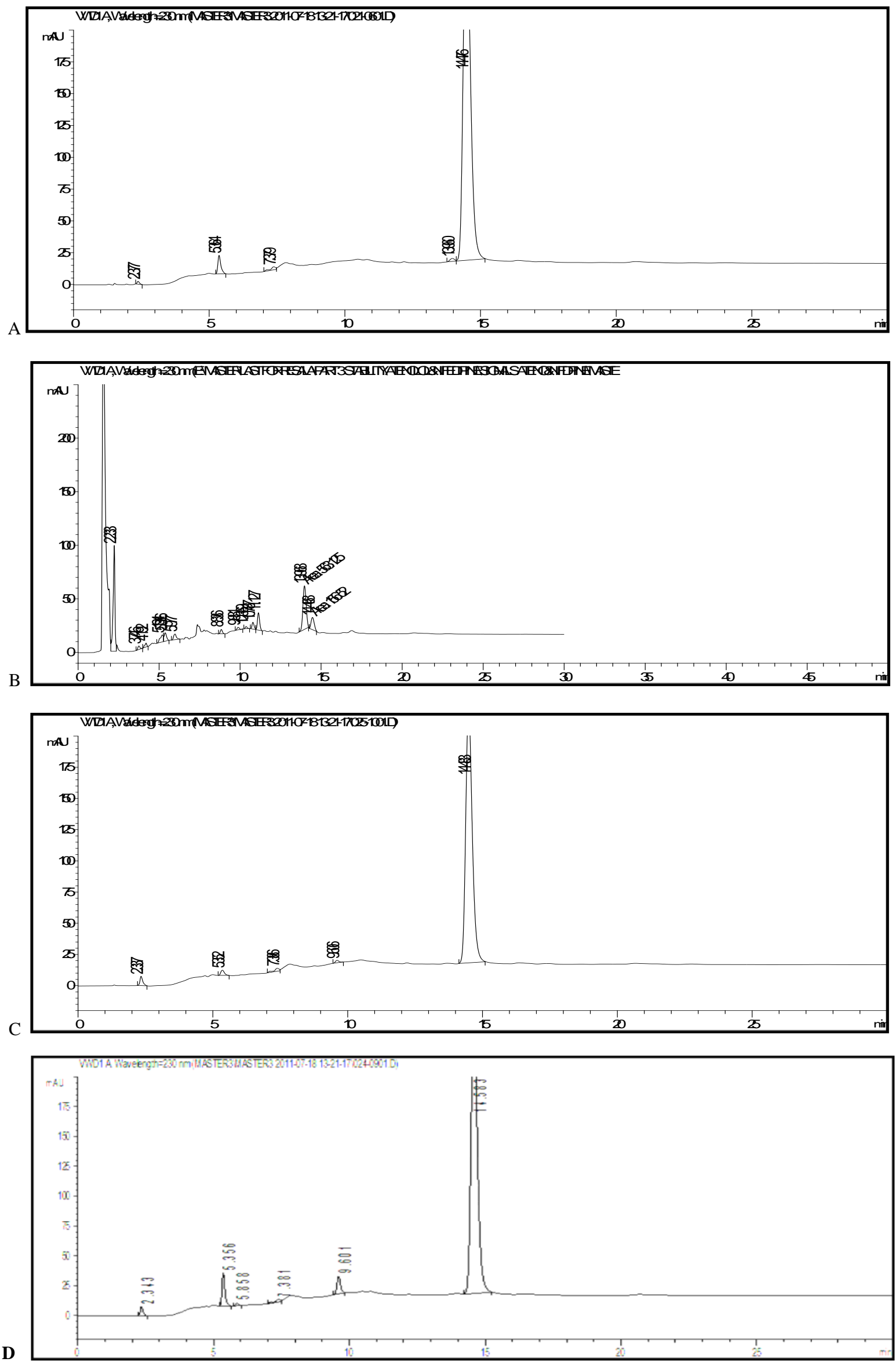

Fig. 4: Stress degradation of Nifedipin., a: Nifedipine after treatment with $\mathrm{H}_{2} \mathrm{O}_{2}$., b: Nifedipine after treatment with $1 \mathrm{~N}$ HCl., c: Nifedipine powder after exposure to heat $60^{\circ} \mathrm{C}$ for 4 hours., d: Nifedipine after exposure to UV light at suntest ${ }^{\circledR}$ for 4 hours 


\section{Application}

The analysis of atenolol and nifedipine in Tenolate $\mathrm{SR}^{\circledR}$ (table 4) capsules showed high accuracy with recovery of $100.78 \pm 0.98$ and $100.65 \pm 1.013 \%$, respectively. The results were compared with a reported method (Vidyadhara et al., 2012) using $\mathrm{t}$ - and F-values and there was no significant difference.

\section{Robustness of the method}

The robustness of the present method was evaluated in the terms of temperature, flow rate, time to reach $50 \% \mathrm{ACN}$ in mobile phase, wavelength of detection, salt concentration and injection volume (table 5). The slight variations in the examined factors had no significant effect on the shape of the peak. The results indicate that the method is more sensitive to changes in flow rate.

\section{CONCLUSIONS}

A valid and fast stability indicating HPLC-method for simultaneous quantification of atenolol and nifedipine is established. Compared with the published methods this method represents a good reduction of the time. With the proposed method a satisfactory separation of atenolol and nifedipine both from each other and from the degradation products and pharmacopeoial impurities was achieved. Extended linear range and rapid analysis time was carried out. A high recovery of both drugs in formulation was achieved. The proposed method ensured a precise and accurate determination of atenolol and nifedipine in oral capsules formulation and is stability indicating method. No interference from the excipients was noticed.

\section{ACKNOWLEDGMENT}

The authors thank the above-mentioned companies for the friendly supply of analytes and column.

There is no any conflict of interest.

\section{REFERENCES}

Al-Ghannam SM, Al-Olyan AM. Spectrofluorometric determination of nicardipine, nifedipine and isradipine in pharmaceutical preparations and biological fluids. Central Eur J Chem, 2008; 6: 222-228.

Asthana S, Kaur V, Chawla P, Saraf SA. Rapid and sensitive HPLC-UV method for simultaneous estimation of nifedipine, nateglinide and lovastatin: quantitative application to polypill based synthetic ternary mixture. Inter J Pharm Tech Res, 2010; 2: 682-688.

Azzam KA, Elbashir AA, Elbashir MA, Saad B, Hamid SA. Simultaneous determination of atenolol and chlorthalidone in pharmaceutical preparations by capillary-zone electrophoresis. Anal Letters, 2009; 42: 1458-1470.

Belal F, Sharaf El-Din M, Aly F, Hefnawy M, El-Awady M. Stability-indicating HPLC method for the determination of atenolol in pharmaceutical preparations. J Chromatogr Sep Tech, 2013; 4: 164, 1-7.

Bing LI, De -fu H, Fei L. HPLC determination of atenolol and nifedipine in compound atenolol tablets. Chinese J Pharm Anal, 2004; 5: 485-486.

Elhenawee M, Hashem H, Ibrahim AE. Comparison between calixarene and conventional HPLC-stationary phases concerning with separation of antihypertensive drugs. J Liq Chromatogr Rel Tech, 2014; 37: 1-25.
ElRies MA. Indirect atomic absorption spectrometric (AAS) determination of atenolol. Anal Letters, 1995; 28: 1629-1639.

El Walily AF. Analysis of nifedipine-acebutolol hydrochloride binary combination in tablets using UV-derivative spectroscopy, capillary gas chromatography and high performance liquid chromatography. J Pharm Biomed Anal 1997; 16: 21-30.

Ferraro MCF, Castellano PM, Kaufman TS. Chemometricsassisted simultaneous determination of atenolol and chlorthalidone in synthetic binary mixtures and pharmaceutical dosage forms. Anal Bioanal Chem, 2003; 377: 1159-1164.

Gajewska M, Glass G, Kostelecki J. Spectrofluorimetric determination of propranolol and atenolol. Acta Poloniae Pharm, 1992; 49: $1-4$.

Guidance for Industry: Q2B of Analytical Procedures; Methodololgy: International Conference of Harmonization (ICH). Nov. 1996.

Handa T, Singh S, Singh IP. Characterization of a new degradation product of nifedipine formed on catalysis by atenolol: A typical case of alteration of degradation pathway of one drug by another. J Pharm Biomed Anal, 2014; 89: 6- 17.

Hashem H, Ibrahim A, Elhenawee M. Chromatographic analysis of some drugs employed in erectile dysfunction therapy: Qualitative and quantitative studies using calixarene stationary phase. J Sep Sci, 2014; 37: 2814-2824.

Hui GJ, Hai DS, Shui WH. Determination of atenolol and nifedipine in atenolol compound tablets by HPLC. Chineese J Pharm, 2004; 1: 39-40.

Kallem RR, Inamadugu JK, Ramesh M, Seshagirirao JV. Sensitive LC-MS/MS-ESI method for simultaneous determination of nifedipine and atenolol in human plasma and its application to a human pharmacokinetic study. Biomed Chromatogr, 2013; 27: 349-55.

Kasture AV, Ramteke M. Simultaneous UV-spectrophotometric methods for the estimation of atenolol and nifedipine in solid dosage forms. Indian J Pharm Sci, 2005; 67: 752-754.

Martens J, Banditt P, Meyer FP. Determination of nifedipine in human serum by gas chromatography-mass spectrometry: validation of the method and its use in bioavailability studies. J Chromatogr B, 1994; 660: 297-302

Ohkubo T, Noro H, K Sugawara. High performance liquid chromatographic determination of nifedipine and a trace photodegradation product in hospital preparations. J Pharm Biomed Anal, 1992; 10: 67-70.

Prasad, CVN, Parihar C, Sunil K, Parimoo P. Simultaneous determination of amiloride $\mathrm{HCl}$, hydrochlorothiazide and atenolol in combined formulations by derivative spectroscopy. J Pharm Biomed Anal, 1998; 17: 877-884.

Prashanth KN, Basavaiah K. Sensitive spectrophotometric determination of atenolol in pharmaceutical formulations using bromatebromide mixture as an eco-friendly brominating agent. J Anal Methods Chem, 2012; 2012: 1-12.

Prichard BN, Cruickshank JM, Graham BR. Beta-adrenergic blocking drugs in the treatment of hypertension. Blood Pressure, 2001; 10: 366-386.

Pyramides G, Robinson JW, Zito SW. The combined use of DSC and TGA for the thermal analysis of atenolol tablets. J Pharm Biomed Anal, 1995; 13: 103-110.

Ramteke M, Kasture A, Dighade N. Development of high performance thin layer chromatographic method for simultaneous estimation of atenolol and nefidipine in combined dosage form. Asian J Chem, 2010; 22: 5951-5955.

Sable Kunal S, Ghadge NN, Hole MB, Gadhave MV. Development of a UV-spectrophotometric method for the simultaneous determination of nifedipine and atenolol in combined dosage form. Inter $\mathbf{J}$ Instit Pharm Life Sci, 2012; 2: 381-389.

Shamsipur M, Hemmateenejad B, Akhond M, Javidnia K, Miri R. A study of the photo-degradation kinetics of nifedipine by multivariate curve resolution analysis. J Pharm Biomed, 2003; 31: 1013-1019

Shapovalov VA. Determination of nifedipine by differential pulse adsorptive stripping polarography. J Anal Chem, 2002; 57: 157-158. 
Singh S, Jain R. Simultaneous spectrophotometric determination of atenolol and amlodipine besylate from dosage forms. Indian Drugs, 1997; 34: 678-679.

Squellaa JA, Barnafib E, Pernac S, Nuñez-Vergarac LJ. Nifedipine: differential pulse polarography and photo-decomposition. Talanta, 1989; 36: 363-366.

Stanley NN, Thirkettle JL, Varma MP, Larkin H, Heath ID. Efficacy and tolerability of atenolol, nifedipine and their combination in the management of hypertension. Drugs, 1988; 35: 29-35.

Sweetman S.C. 2006. Martindale, The Complete Drug Reference, 37th ed. Pharmaceutical Press, London.

Taei M, Hasanpour F, Shavakhi M. Application of N-4,4'azodianiline(ferrocenyl Schiff base) for electrocatalytic determination of atenolol on modified carbon paste electrode. Iranian Chem Comm, 2015; 3: 19-31.

The British Pharmacopoeia, Her Majesty's Stationery Office, London, UK, 2011.

Umapathi P. Determination of atenolol, nifedipine, aspirin and dipyridamole in tablet preparations by second-order derivative spectrophometry. Inter J Pharm, 1994; 108: 11-19.
Veronico M, Rango G, Vitusche C. Simultaneous assay of atenolol and nifedipine by derivative spectrophotometry and GC. Spectroscopy Letters, 1995; 28: 407-415.

Vidyadhara S, Sasidhar RLC, Praveen Kumar B, Pramarao NT, Riharita N. Method development and validation for simultaneous estimation of atenolol and nifedipine in pharmaceutical dosage forms by RP-HPLC. Oriental J Chem, 2012; 28: 1691-1696.

Yilmaz B, Arslan S. Determination of atenolol in human urine by gas chromatography-mass spectrometry method. J Chromatogr Sci, 2011; 49: 365-369.

\section{How to cite this article:}

Hisham Hashem, Adel Ibrahim, Magda Elhenawee. A novel stability indicating HPLC-method for simultaneous determination of atenolol and nifedipine in presence of atenolol pharmacopeoial impurities. J App Pharm Sci, 2015; 5 (08): 017-025. 